Check for updates

Cite this: RSC Med. Chem., 2021, 12, 2053

Received 8th May 2021

Accepted 11th October 2021

DOI: 10.1039/d1md00163a

rsc.li/medchem

\section{ItaCORMs: conjugation with a CO-releasing unit
greatly enhances the anti-inflammatory activity of \\ ItaCORMs: conjugation with a CO-releasing unit
greatly enhances the anti-inflammatory activity of itaconates $\uparrow$}

\author{
Bernhard M. Krause, (D) a Britta Bauer, ${ }^{b}$ Jörg-Martin Neudörfl, \\ Thomas Wieder ${ }^{\star b c}$ and Hans-Günther Schmalz (D)*a
}

\begin{abstract}
Endogenous itaconate as well as the gasotransmitter $\mathrm{CO}$ have recently been described as powerful antiinflammatory and immunomodulating agents. However, each of the two agents comes along with a major drawback: Whereas itaconates only exert beneficial effects at high concentrations above $100 \mu \mathrm{M}$, the uncontrolled application of $\mathrm{CO}$ has strong toxic effects. To solve these problems, we designed hybrid prodrugs, i.e. itaconates that are conjugated with an esterase-triggered CO-releasing acyloxycyclohexadiene-Fe(CO) 3 unit (ItaCORMs). Here, we describe the synthesis of different ItaCORMs and demonstrate their anti-inflammatory potency in cellular assays of primary murine immune cells in the low $\mu$ molar range $(<10 \mu \mathrm{M})$. Thus, ItaCORMs represent a promising new class of hybrid compounds with high clinical potential as anti-inflammatory agents
\end{abstract}

\section{Introduction}

Dimethyl fumarate (DMF; 1) represents one of the structurally simplest active pharmaceutical ingredients. Since its accidental discovery, it has become one of the most frequently used immunomodulatory and anti-inflammatory agents in the clinics, especially for the treatment of psoriasis and multiple sclerosis. ${ }^{1}$ As an electrophilic molecule DMF was shown to covalently modify cysteine residues, thereby inactivating proteins such as the glycolytic enzyme glyceraldehyde 3-phosphate dehydrogenase (GAPDH) and causing downregulation of aerobic glycolysis. Another relevant target of DMF is the Kelch-like ECH-associated protein 1 (KEAP1) which is involved in inflammatory processes by suppressing the (erythroid-derived 2)-related factor 2 (Nrf2). ${ }^{2}$

The endogenous metabolite itaconic acid (IA; 2) has recently been identified as an even stronger antiinflammatory and immunoregulatory agent ${ }^{3}$ also modulating macrophage function by activating Nrf2 via alkylation of cysteine residues of KEAP1. Moreover, the cell-permeable

\footnotetext{
${ }^{a}$ University of Cologne, Department of Chemistry, Greinstr. 4, 5939 Köln, Germany. E-mail: schmalz@uni-koeln.de

${ }^{b}$ University Medical Center Tübingen, Department of Dermatology, Liebermeisterstr. 25, 72076 Tübingen, Germany

${ }^{c}$ Physiologisches Institut, Abteilung für Vegetative und Klinische Physiologie, Eberhard-Karls-Universität Tübingen, Wilhelmstr. 56, 72074 Tübingen, Germany $\dagger$ Electronic supplementary information (ESI) available: Synthetic procedures, substance data, spectra, CO-release studies, and cell-biological studies. CCDC 2077461 and 2077462. For ESI and crystallographic data in CIF or other electronic format see DOI: 10.1039/d1md00163a
}

derivative 4-octyl itaconate (4-OI; 3) proved to be a strong protective agent against lipopolysaccharide (LPS) induced lethality of human peripheral blood mononuclear cells (PBMCs) in vivo by reducing cytokine production. ${ }^{4}$ In another study, the extensive metabolic rewiring of inflammatory macrophages, including regulation of the IкB $\zeta-\mathrm{ATF} 3$ inflammatory axis, was shown to be linked to the induction of electrophilic stress caused by IA and even stronger by its membrane-permeable derivative dimethyl itaconate (DMI; 4) by selectively inhibiting a subset of cytokines, including IL-6 and IL-12. ${ }^{5}$ These effects were confirmed in subsequent studies, and the promising potential of itaconate-derived compounds as therapeutic agents is reflected by intense ongoing research activities in leading laboratories. ${ }^{6}$

Another most simple anti-inflammatory, immunomodulating and cytoprotective molecule is carbon monoxide (CO), a so-called gasotransmitter which, like NO, displays highly beneficial effects at very low concentrations. ${ }^{7}$ To avoid the risks and toxicity associated with administration of $\mathrm{CO}$ by inhalation, the development of methods for the targeted delivery of $\mathrm{CO}$, particularly through the use of COreleasing molecules (CORMs), has become a fascinating field of drug discovery. ${ }^{8}$ While a variety of CORMs have been reported in the literature, most of them do not meet the requirements for pharmaceutical application. A promising concept to meet the challenge of controlled (intracellular) CO release is the use of enzyme-triggered CORMs (ET-CORMs). ${ }^{9}$ In this context, we introduced acyloxydiene- $\mathrm{Fe}(\mathrm{CO})_{3}$ complexes activated by enzyme-induced hydrolysis of the 
ester moiety. ${ }^{10}$ In contrast to the stable ester prodrugs, the resulting dienol-Fe(CO) $)_{3}$ complexes, such as rac-5, undergo rapid oxidation under physiological conditions, leading to the release of up to three molecules of CO causing the expected pronounced biological effects (Scheme 1). Noteworthy, simultaneously formed cyclohexenone (6) and ferric ions $\left(\mathrm{Fe}^{3+}\right)$ were found not to affect cell viability at the relevant concentrations. ${ }^{11}$ Another by-product of the enzymatic ester cleavage of ET-CORMs is a carboxylic acid corresponding to the acyloxy unit. While first studies on our esterase-triggered system were conducted only with biologically non-active acid residues, such as acetate or homologous alkanoic acids, we were aware that the ETCORM concept ideally allows a bioactive acid to be concomitantly released together with $\mathrm{CO}$ which could act synergistically. Hence, methyl fumarate-derived ET-CORMs (FumET-CORMs) were presented as one of the first bifunctional CORMs which exhibited a substantially improved anti-inflammatory effect as compared to the clinically used drug DMF (1). ${ }^{12}$ In a somewhat related fashion, (untriggered) hybrid CORMs, derived from fumarates and $\mathrm{Co}, \mathrm{Mn}$ or $\mathrm{Ru}$ carbonyl complex units have been reported by Motterlini and coworkers. ${ }^{13}$

Inspired by the promising properties of the FumETCORMs and taking into account the significantly higher bioactivity of DMI $(\mathbf{4})^{3-5}$ compared to DMF (1), we now envisioned to synthesize and investigate itaconate-derived ET-CORMs (ItaCORMs) which we expected to exhibit even more powerful anti-inflammatory effects (Scheme 1).

\section{Results}

\section{Synthesis of ItaCORMs}

According to our previously established procedure, ItaCORMs were prepared from the cyclohexenone-derived silyl dienol ethers rac-9a or rac-9b, respectively (Scheme 2). ${ }^{9 c}$ For this purpose, the silyl group of $r a c-9 a / b$ was first cleaved off with TBAF in THF and the resulting iron-complexed dienolate alkoxides were reacted with the respective itaconate-derived acid chlorides prepared in situ using Ghosez's reagent (10). ${ }^{14}$ The required mono-alkyl itaconates were either commercially obtained $(\mathbf{1 2 a} / \mathbf{1 2 b})$ or synthesized $(\mathbf{1 1 a} / \mathbf{1 1 b})$ from itaconic acid following a modified literature protocol. ${ }^{15}$ These compounds were also employed as controls in the biological

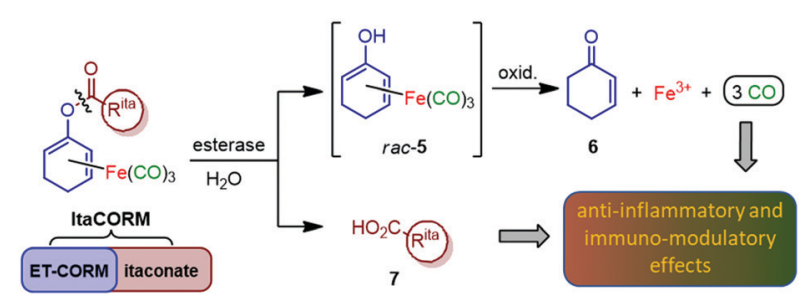

Scheme 1 Design of anti-inflammatory compounds (ItaCORMs) acting by intracellular esterase-triggered release of both carbon monoxide (CO) and an itaconate (7).

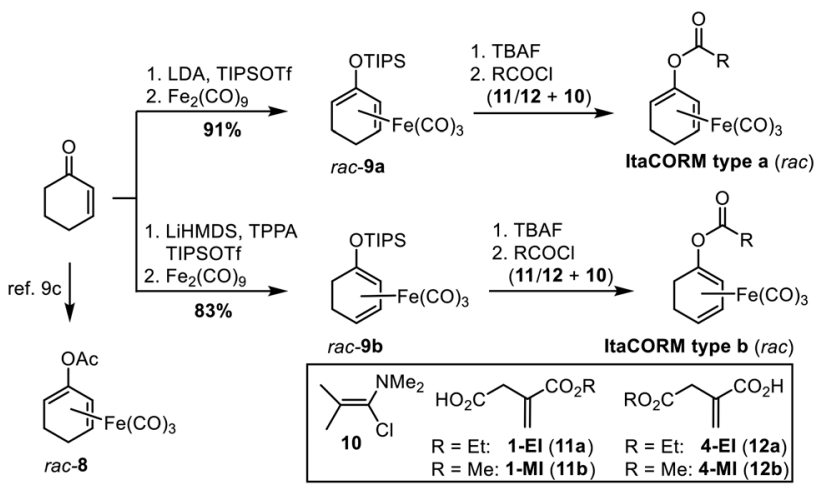

Scheme 2 Synthesis of various itaconate-derived acyloxycyclohexadiene- $\mathrm{Fe}(\mathrm{CO})_{3}$ complexes as potential CO-releasing molecules (ItaCORMs). LDA = lithium diisopropylamide; TIPSOTf = triisopropylsilyl trifluoromethanesulfonate; TPPA = tripyrolidinophosphoric acid triamide; TBAF = tetrabutylammonium fluoride.

investigations (vide infra). As an additional reference substance, the known acetic acid-derived ET-CORM rac-8 was prepared as previously described. ${ }^{10}$

According to the general protocol (Scheme 2), a set of eight (racemic) ItaCORMs were prepared in good to excellent yield (Fig. 2). Noteworthy, initial attempts to perform the esterification of the intermediate dienolate-Fe(CO) complexes under Steglich-type conditions (previously used to prepare fumarate-derived CORMs) ${ }^{12}$ completely failed in the itaconate series.

The prepared (racemic) ItaCORMs were all characterized by the common spectroscopic methods and proved to be stable and easy to handle compounds, which can be stored for longer periods of time in the fridge without decomposition. The structures of the methyl ester derivatives ItaCORM $\mathbf{3 b}$ and ItaCORM $\mathbf{4 b}$ were additionally confirmed by single crystal X-ray analysis. (Fig. 3).

\section{In vitro CO-release}

To probe the proposed ability of the ItaCORMs to undergo enzyme-triggered cleavage/oxidation under concomitant carbon monoxide (CO) release (Scheme 1) samples of the complexes were treated with pig liver esterase (PLE) in a DMSO/phosphate buffer mixture, and the CO release was monitored over a period of $100 \mathrm{~h}$ by means of headspace gas chromatography. While virtually no $\mathrm{CO}(\leq 0.05$ equiv.) was released in the absence of PLE (control) we found that significant amounts of CO were liberated from the ItaCORMs in the presence of PLE (Fig. 4). Interestingly, but not completely unexpected, ${ }^{10,12}$ the

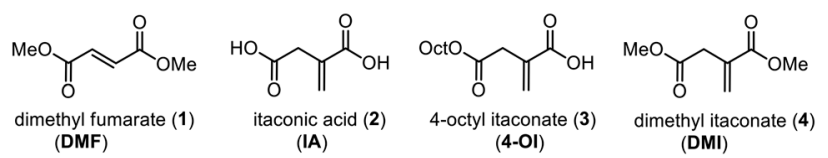

Fig. 1 Dimethyl fumarate and itaconic acid derivatives displaying pronounced anti-inflammatory effects. 


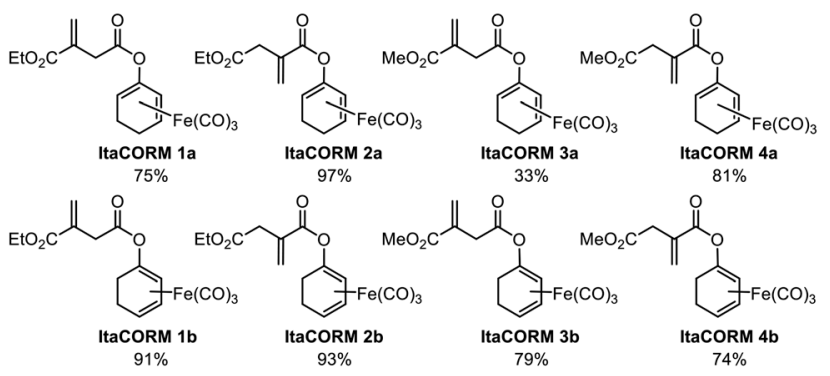

Fig. 2 Itaconate-derived CO-releasing molecules (ItaCORMs) synthesized according to Scheme 2.

ItaCORMs of type a, with the acyloxy substituent at the "inner" position of the cyclohexadiene- $\mathrm{Fe}(\mathrm{CO})_{3}$ moiety (Fig. 4A), showed a considerably slower CO release in comparison to the "outer" series (Fig. 4B). We also found that ItaCORMs 4a and $\mathbf{4 b}$, derived from 4-methyl itaconate (12b) displayed a stronger tendency to release $\mathrm{CO}$ than the isomers derived from 1-methyl itaconate (11b). In this particular assay, the "best" CO-releasing molecule of the investigated compounds proved to be ItaCORM $\mathbf{4 b}$, which released three full equivalents of $\mathrm{CO}$ within 17 hours (Fig. 4B). We would like to emphasize, however, that these in vitro-measured CO-release kinetics reflect the sum of several steps including of the ester cleavage and the oxidation of the primary dienol-Fe(CO) $)_{3}$ complexes of type rac-5 (Scheme 1).

\section{Biological studies}

To investigate the expected anti-inflammatory activity of ItaCORMs we employed an established in vitro model for the analysis of inflammatory responses utilizing bone marrowderived dendritic cells (BMDCs) stimulated by lipopolysaccharide (LPS). ${ }^{12,16}$ At first, we determined the cytotoxicity of ItaCORMs $1 \mathbf{a} / \mathbf{b}$ and $\mathbf{2 a} / \mathbf{2} \mathbf{b}$ by means of the XTT assay, $^{12}$ and an assay based on the release of lactate dehydrogenase (LDH). ${ }^{17}$ While these compounds showed no substantial toxicity up to a concentration of $15 \mu \mathrm{M}$, a rapid decrease of the cell viability was observed at concentrations of $\geq 25 \mu \mathrm{M}$ for all ItaCORMs with the exception of ItaCORM 1a (see Fig. SI-9†). Therefore, all subsequent experiments were performed using non-toxic concentrations $\leq 15 \mu \mathrm{M}$.

As previously shown, the envisaged induction of an antiinflammatory type II phenotype of dendritic cells importantly depends both on the regulation of HO-1 and STAT1 signaling

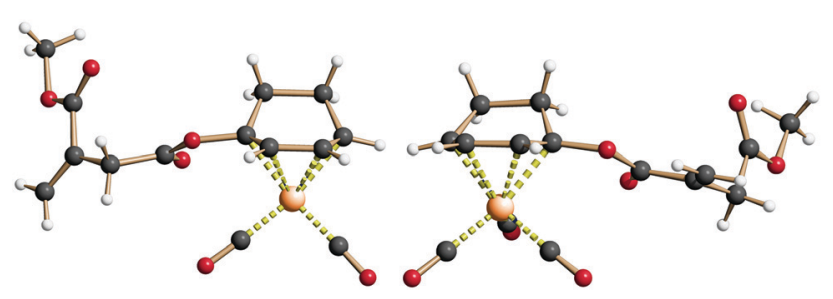

Fig. 3 Structure of ItaCORM 3b (left) and ItaCORM 4b (right) in the crystalline state.
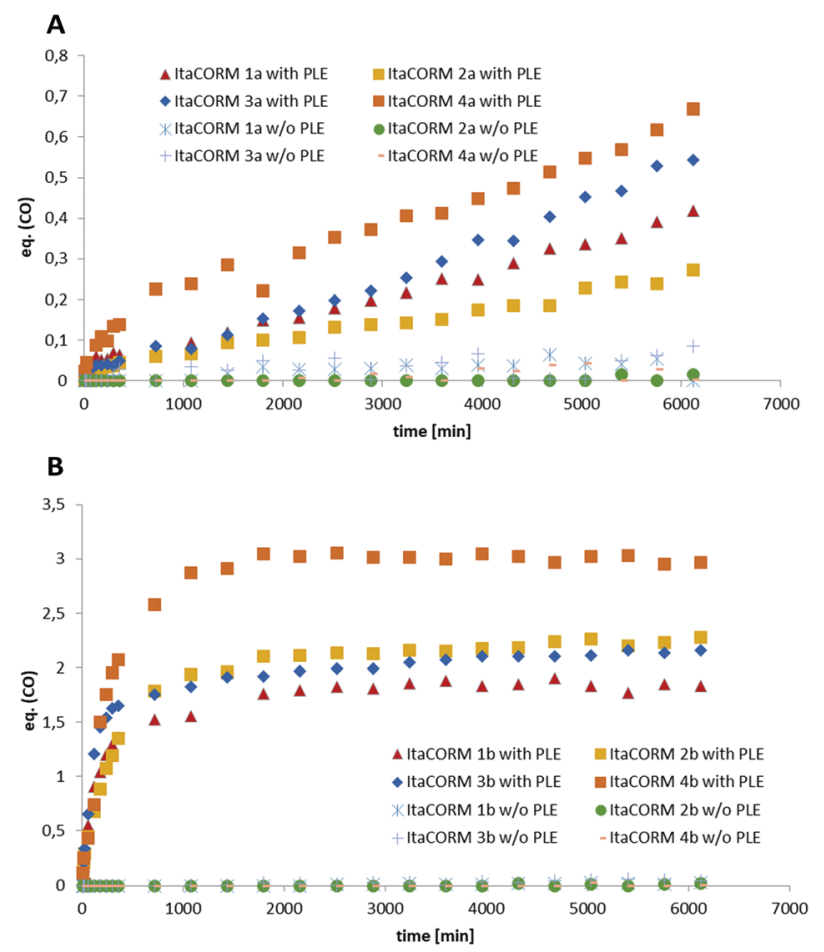

Fig. 4 Quantification of the PLE-triggered CO release properties of ItaCORMs. A: ItaCORMs of type a. B: ItaCORMs of type b. Each complex $(36 \mu \mathrm{mol})$ was dissolved in $0.2 \mathrm{~mL}$ of DMSO and $1.0 \mathrm{~mL}$ of phosphate buffer ( $\mathrm{pH} 7.4$ ) before $15 \mathrm{mg}$ of PLE ( $\geq 24$ units per $\mathrm{mg}$ ) were added. The resulting mixture was stirred at $37^{\circ} \mathrm{C}$ and the released $\mathrm{CO}$ was measured via headspace gas chromatography. Samples of each ItaCORM in the absence of PLE were analyzed in via the same method as a control.

pathways and on the associated inhibition of inflammatory cytokines IL-23 and IL12-p70. ${ }^{12}$ Hence, we next analyzed the effects of ItaCORMs on these signaling mechanisms (Fig. 5). And indeed, HO-1 was strongly upregulated upon treatment of the cells with ItaCORMs $\mathbf{1 b}, \mathbf{2} \mathbf{a}$ and $\mathbf{2} \mathbf{b}$, in contrast to STAT1, which remained more or less unchanged. Noteworthy, the effects of these dual-active compounds proved to be much stronger than those of the control substances 1-EI (11a), 4-EI (12a) and rac-8, respectively, which only release either itaconic acid or CO (Fig. 1).

As another activity, we also observed a strong downregulation of inflammatory cytokines IL-23 and IL12p70 upon treatment of LPS-stimulated BMDCs with ItaCORMs (Fig. 6). While ItaCORM 1a again showed only minor effects (as in the HO-1 induction), ItaCORMs 1b, 2a, and $\mathbf{2 b}$ caused a pronounced reduction of cytokine levels. Again, the latter compounds proved to be much more potent than any of the controls applied at the same concentration. Noteworthy, dimethyl itaconate (DMI), used as a highly active benchmark compound in the recent literature, ${ }^{5}$ showed only a minor effect at these concentrations.

Since the itaconate esters derived from different alcohols may differ in their biological activity, ${ }^{5}$ we also investigated the methyl itaconate-derived ItaCORMs $\mathbf{3 a}, \mathbf{b}$ and $\mathbf{4 a}, \mathbf{b}$ in 
A

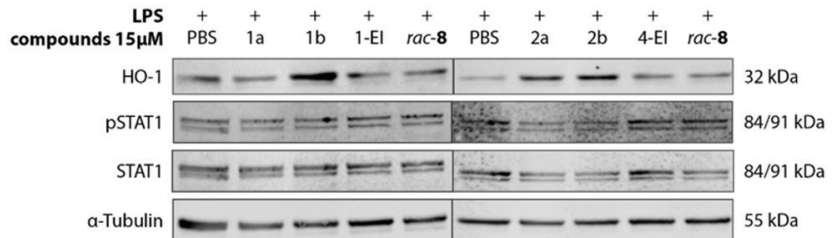

B

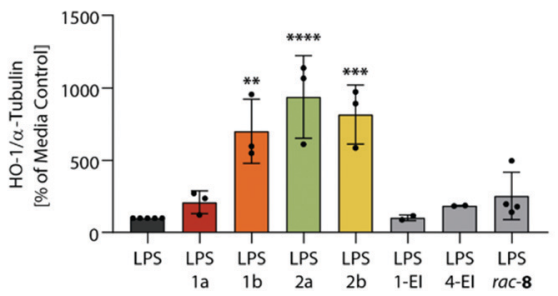

C

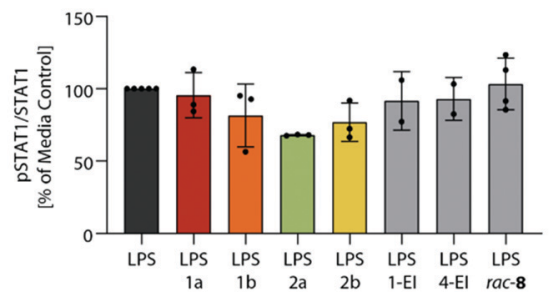

Fig. 5 Modulation of $\mathrm{HO}-1$ and STAT1 signaling pathways by ItaCORMs. BMDCs were stimulated with $1 \mu \mathrm{g} \mathrm{ml}^{-1}$ LPS and coincubated with PBS, in the presence of $15 \mu \mathrm{M}$ of ItaCORMs, or 1-El, 4EI and rac-8 as control substances. After $2 \mathrm{~h}$, cell lysates were harvested and analyzed by Western blot using HO-1, STAT1, PSTAT1 and $\alpha$-tubulin antibodies. (A) Representative Western blots. As loading control $\alpha$-tubulin was used. (B and C) The video-densiometric quantification of the HO-1/ $\alpha$-tubulin (B) and pSTAT1/STAT1 $(C)$ ratios are shown in percent of the LPS-treated control group. Values are means \pm SEM $(n=2-5) ; * *, p \leq 0.01 ; * * * *, p \leq 0.0001$ (ANOVA with Tukey post hoc test).

comparison to the ethyl esters (ItaCORMs 1a, 1b, 2a, 2b) with regard to their ability to inhibit the expression of inflammatory cytokines (Fig. 7).

We found, that at the low concentration of $7 \mu \mathrm{M}$ the methyl esters caused an even stronger decrease of IL-23 and IL-12p70 than the initially studied ethyl esters. As Fig. 7 reveals, the relative activity within the two series proved to be similar. Remarkably, an almost complete suppression of IL23 was observed upon treatment of BMDCs with ItaCORMs $3 \mathbf{b}, \mathbf{4 a}$ or $\mathbf{4 b}$ at a concentration of $15 \mu \mathrm{M}$ (ESI $\dagger$ Fig. S10). At this concentration, IL-12p70 totally disappeared in the presence of all ItaCORMs investigated except for 1a and 3a, the latter being also highly active at this concentration. Fig. 7 also indicates again the superb anti-inflammatory efficacy of the ItaCORMs as compared to $7 \mu \mathrm{M}$ dimethyl itaconate (DMI), which displayed comparable effects only at much higher concentrations $(100 \mu \mathrm{M})$.

\section{Discussion}

While gaseous CO is highly toxic upon inhalation it has beneficial cellular effects at low concentrations. Physiologically, CO is produced by HO-1, the enzyme that catalyzes the rate-limiting step in heme degradation. CO has

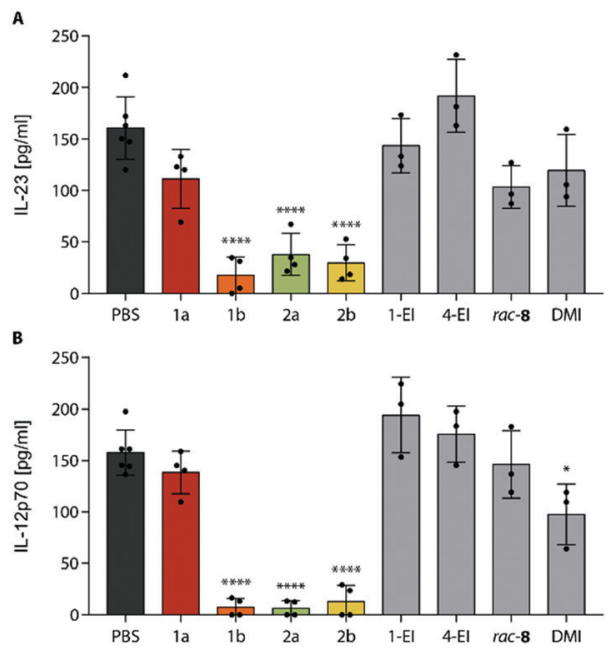

Fig. 6 Strong inhibition of inflammatory cytokines by ItaCORMs. Concentrations of IL-23 (A) and IL-12p70 (B) were determined in the supernatant of BMDCs stimulated with $1 \mu \mathrm{g} \mathrm{ml}^{-1} \mathrm{LPS}$ and co-incubated with PBS, $15 \mu \mathrm{M}$ ItaCORMs, or 1-EI, 4-EI, rac-8, and DMI as control substances for $24 \mathrm{~h}$. Values are means $\pm \operatorname{SEM}(n=3-6) ; *, p \leq 0.05$; ****, $p \leq 0.0001$ (ANOVA with Tukey post hoc test).

been shown to mediate the beneficial effects of $\mathrm{HO}-1$, including protection against oxidative stress, modulation of the inflammatory response and regulation of angiogenesis. ${ }^{18}$ Our data that ItaCORMs induce HO-1 at low concentrations therefore point to a positive feed-forward mechanism that leads to sustained activation of the HO-1/CO axis. Furthermore, ItaCORMs as presented in this study combine esterase-triggered (intracellular) co-release of CO and an antiinflammatory itaconate. The results indicate that the two agents then synergistically activate two pathways: one leading to HO-1-dependent downregulation of IL-23 and the other one resulting in repression of IL-12p70, presumably via inhibition of IRF8 or I $\kappa$ B $\zeta$ (Fig. 8). Together, this promotes an anti-inflammatory type II immune response. ${ }^{19}$ Regarding this, ItaCORMs proved to be by far more effective than the single treatment with an itaconate, $\mathrm{CO}$ alone or other related CORMs. Particularly, the concentrations of itaconates required to induce anti-inflammatory cellular effects in the absence of a CO source are in the range of $100 \mu \mathrm{M}^{4,5}$ This is about 10 times higher than the effective concentration of ItaCORMs described in the study.

\section{Experimental}

\section{General procedure for the synthesis of ItaCORMs}

(Reactions were run on a 127-520 $\mu \mathrm{mol}$ scale under argon.) In a Schlenk tube, a $0.3 \mathrm{M}$ solution of the respective itaconic monoester (11 or 12) (1.4-1.5 eq.) in $\mathrm{CH}_{2} \mathrm{Cl}_{2}$ was cooled to 0 ${ }^{\circ} \mathrm{C}$. Ghosez's reagent (1.5-1.7 eq.) was added and the mixture was stirred for $1 \mathrm{~h}$ (M1). In a separate Schlenk tube, a 0.3-0.5 $\mathrm{M}$ solution of complex rac-9a or rac-9b (1.0 eq.) in $\mathrm{CH}_{2} \mathrm{Cl}_{2}$ was cooled to $0^{\circ} \mathrm{C}$ and TBAF ( $1 \mathrm{M}$ in THF, 1.0 eq.) was added dropwise under stirring (M2). After 10 min solution M2 was 

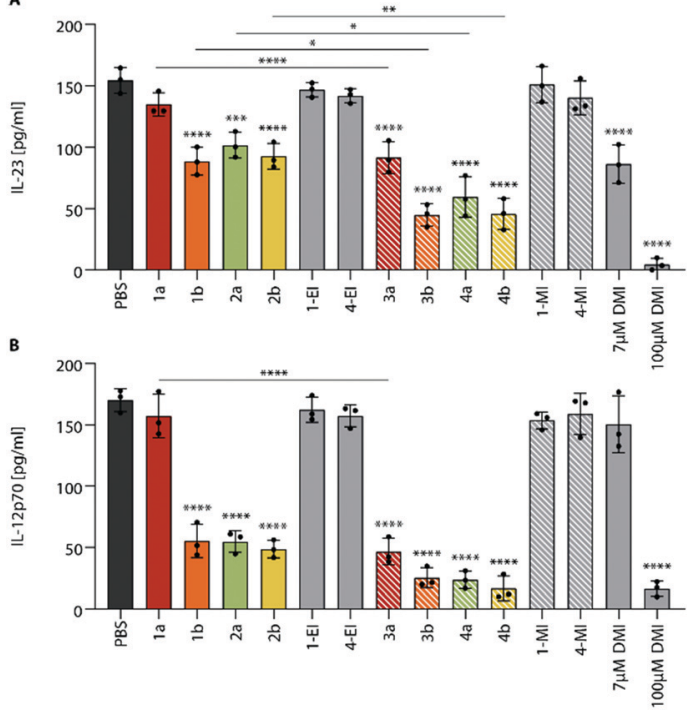

Fig. 7 Comparison of ethyl itaconate (fully colored bars) and methyl itaconate (dashed bars) derived ItaCORMs. BMDCs were stimulated with $1 \mu \mathrm{g} \mathrm{ml}^{-1}$ LPS and co-incubated with PBS, ethyl-ItaCORMs 1a, 1b, $2 a, 2 b$, methyl-ItaCORMs $3 a, 3 b, 4 a, 4 b$ or control compounds $(7 \mu \mathrm{M})$. After $24 \mathrm{~h}$ of incubation, cell culture supernatants were collected and analyzed for IL-23 (A) and IL-12p70 (B) cytokine levels. Values are means $\pm \operatorname{SEM}(n=3) ; *, p \leq 0.05 ; * *, p \leq 0.01 ; * * *, p \leq 0.001 ; * * * *, p$ $\leq 0.0001$ (ANOVA with Tukey post hoc test).

transferred dropwise into $\mathrm{M} 1$ at $0{ }^{\circ} \mathrm{C}$. The resulting solution was stirred at $0{ }^{\circ} \mathrm{C}$ for $10 \mathrm{~min}$ and then for $16-21 \mathrm{~h}$ at room temperature. The solvent was removed under reduced pressure and the crude product was purified by column chromatography on $\mathrm{SiO}_{2}$ (Cyhex/EtOAc; 20/1 to 5/1) to give the respective ItaCORM. For details, including substance data, PLE-triggered CO-release experiments and biochemical investigations, see the ESI. $\dagger$

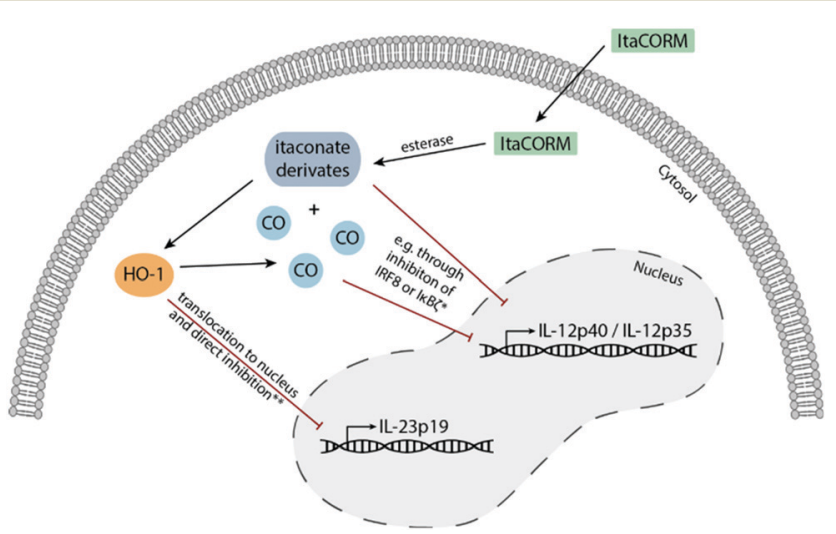

Fig. 8 Possible mechanisms of the anti-inflammatory activity of ItaCORMs. After cleavage of ItaCORMs by esterases, itaconate and CO are released into the cytoplasm of the cell. This results in the induction of heme oxygenase (HO-1), which, after translocation into the nucleus, is responsible for the inhibition of IL-23 expression. Furthermore, itaconate and $\mathrm{CO}$ cause decreased levels of II-12, possibly due to inhibition of transcription factors, e.g. the interferon regulatory factor 8 (IRF8) or I $\mathrm{KB} \zeta$ as the inhibitor of $\mathrm{NF}-\kappa \mathrm{B} \zeta$.
Mice

Wildtype C57BL/6J mice were maintained and bred under specific pathogen-free conditions at the premises of the Eberhard Karls University Tübingen. Mouse handling and isolation of cells from bone marrow were approved by the "Einrichtung für Tierschutz, Tierärztlichen Dienst und Labortierkunde" and the "Regierungspräsidium Tübingen" and were performed with female and male animals aged 8 weeks and older. All animal procedures were performed in accordance with the Guidelines for Care and Use of Laboratory Animals of the University of Tübingen Germany. All animal experiments were approved by the local authorities (Regierungspräsidium Tübingen, Germany).

\section{Isolation of BMDCs}

Bone marrow derived dendritic cells were isolated as previously described. $^{20}$ In brief, bone marrow cells were obtained from the femurs and tibias of mice. Differentiation of cells into BMDCs was performed by culture in DMEM media supplemented with $10 \%$ fetal calf serum, $1 \%$ nonessential amino acids, 1\% sodium pyruvate, 1\% HEPES, 1\% antibiotics, $25 \mu \mathrm{M} \quad \beta$-mercaptoethanol and $20 \mathrm{ng} \mathrm{ml}$ recombinant granulocyte-macrophage colony-stimulating factor (GM-CSF). Refreshment with new cell culture medium was performed on days 3 and 6. After 7 days, harvest of immature BMDCs was performed by careful collection of non-adherent cells.

\section{Western blot analysis}

BMDCs were treated as indicated in the figure description and protein expression was analyzed as previously described. ${ }^{12}$ Briefly, cell lysates were separated by SDS-PAGE and blotted onto polyvinylidene difluoride transfer membranes. Protein detection was performed by incubation with HO-1, STAT1, pSTAT1 and $\alpha$-tubulin antibodies and using the Odyssey SA Infrared Imaging System.

\section{Cytokine analysis}

BMDCs were stimulated with LPS and co-incubated with the respective ItaCORMs or control substances as indicated in the figure legend. After $24 \mathrm{~h}$, supernatants of each culture condition were collected and assayed for IL-12p70 and IL-23 levels. ELISA was performed using DuoSet ELISA Mouse IL12p70, DuoSet ELISA Mouse IL-23 and DuoSet Ancillary Reagent Kit 2 (R\&D Systems).

\section{Conclusions}

We have synthesized and chemically characterized a new class of acyloxydiene- $\mathrm{Fe}(\mathrm{CO})_{3}$ complexes which upon esterasetriggered cleavage disintegrate to concomitantly release carbon monoxide (CO) and an itaconate as two important anti-inflammatory and immunomodulating agents. Some of these compounds, especially the 4-methyl itaconate-derived ItaCORMs $\mathbf{4 a}$ and $\mathbf{4 b}$ were then shown in cellular assays to 
induce HO-1 and to strongly inhibit the expression of inflammatory cytokines $\mathrm{IL}-23$ and $\mathrm{IL}-12 \mathrm{p} 70$ at low micromolar concentration. ItaCORMs $\mathbf{4 a}$ and $\mathbf{4 b}$ therefore represent particularly promising anti-inflammatory agents which may deserve further clinical evaluation.

\section{Author contributions}

T. W. and H.-G. S. initiated research; B. M. K. performed chemical syntheses and CO-release studies; B. B. performed biochemical investigations; J.-M. N. performed X-ray crystal structure analyses; B. M. K., B. B., T. W. and H.-G. S. wrote the manuscript.

\section{Conflicts of interest}

There are no conflicts to declare.

\section{Acknowledgements}

This work was supported by the German Science Foundation (project SCHM 857-20-1) and the Wilhelm Sander-Stiftung (Project No. 2020.100.1).

\section{Notes and references}

1 For recent reviews, see: (a) H. A. Blair, Drugs, 2019, 79, 1965-1976; (b) S. Kourakis, C. A. Timpani, J. B. de Haan, N. Gueven, D. Fischer and E. Rybalka, Pharmaceuticals, 2020, 13, 306; and ref. cited therein.

2 (a) M. D. Kornberg, P. Bhargava, P. M. Kim, V. Putluri, A. M. Snowman, N. Putluri, P. A. Calabresi and S. H. Snyder, Science, 2018, 360, 449-453; (b) M. S. Brennan, M. F. Matos, B. Li, X. Hronowski, B. Gao, P. Juhasz, K. J. Rhodes and R. H. Scannevin, PLoS One, 2015, 10, e0120254.

3 (a) R. Li, P. Zhang, Y. Wang and K. Tao, Oxid. Med. Cell. Longevity, 2020, 2020, 5404780; (b) A. Hooftman and L. A. J. O'Neill, Trends Immunol., 2019, 40, 687-698; (c) L. A. J. O'Neill and M. N. Artyomov, Nat. Rev. Immunol., 2019, 19, 273-281; (d) M. Sano, T. Tanaka, H. Ohara and Y. Aso, Appl. Microbiol. Biotechnol., 2020, 104, 9041-9051.

4 E. L. Mills, D. G. Ryan, H. A. Prag, D. Dikovskaya, D. Menon, Z. Zaslona, M. P. Jedrychowski, A. S. H. Costa, M. Higgins, E. Hams, J. Szpyt, M. C. Runtsch, M. S. King, J. F. McGouran, R. Fischer, B. M. Kessler, A. F. McGettrick, M. M. Hughes, R. G. Carroll, L. M. Booty, E. V. Knatko, P. J. Meakin, M. L. J. Ashford, L. K. Modis, G. Brunori, D. C. Sévin, P. G. Fallon, S. T. Caldwell, E. R. S. Kunji, E. T. Chouchani, C. Frezza, A. T. Dinkova-Kostova, R. C. Hartley, M. P. Murphy and L. A. O'Neill, Nature, 2018, 556, 113-117.

5 M. Bambouskova, L. Gorvel, V. Lampropoulou, A. Sergushichev, E. Loginicheva, K. Johnson, D. Korenfeld, M. E. Mathyer, H. Kim, L.-H. Huang, D. Duncan, H. Bregman, A. Keskin, A. Santeford, R. S. Apte, R. Sehgal, B. Johnson, G. K. Amarasinghe, M. P. Soares, T. Satoh, S. Akira, T. Hai, C. de Guzman Strong, K. Auclair, T. P. Roddy, S. A. Biller, M. A. Jovanovic, E. Klechevsky, K. M.
Stewart, G. J. Randolph and M. N. Artyomov, Nature, 2018, 556, 501-504.

6 (a) M. Chen, H. Sun, M. Boot, L. Shao, S.-J. Chang, W. Wang, T. T. Lam, M. Lara-Tejero, E. H. Rego and J. E. Galán, Science, 2020, 369, 450-455; (b) A. Swain, M. Bambouskova, H. Kim, P. S. Andhey, D. Duncan, K. Auclair, V. Chubukov, D. M. Simons, T. P. Roddy, K. M. Stewart and M. N. Artyomov, Nat. Metab., 2020, 2, 594-602; (c) A. Hooftman, S. Angiari, S. Hester, S. E. Corcoran, M. C. Runtsch, C. Ling, M. C. Ruzek, P. F. Slivka, A. F. McGettrick, K. Banahan, M. M. Hughes, A. D. Irvine, R. Fischer and L. A. J. O'Neill, Cell Metab., 2020, 32, 468-478.e467; (d) S.-T. Liao, C. Han, D.-Q. Xu, X.-W. Fu, J.-S. Wang and L.-Y. Kong, Nat. Commun., 2019, 10, 5091; (e) J. Domínguez-Andrés, B. Novakovic, Y. Li, B. P. Scicluna, M. S. Gresnigt, R. J. W. Arts, M. Oosting, S. J. C. F. M. Moorlag, L. A. Groh, J. Zwaag, R. M. Koch, R. ter Horst, L. A. B. Joosten, C. Wijmenga, A. Michelucci, T. van der Poll, M. Kox, P. Pickkers, V. Kumar, H. Stunnenberg and M. G. Netea, Cell Metab., 2019, 29, 211-220.e215; $(f)$ W. Qin, K. Qin, Y. Zhang, W. Jia, Y. Chen, B. Cheng, L. Peng, N. Chen, Y. Liu, W. Zhou, Y.-L. Wang, X. Chen and C. Wang, Nat. Chem. Biol., 2019, 15, 983-991.

7 (a) Key reference: R. Motterlini and L. E. Otterbein, Nat. Rev. Drug Discovery, 2010, 9, 728-743; (b) U. Goebel and J. Wollborn, Intensive Care Med. Exp., 2020, 8, 2; (c) C. Steiger, C. Hermann and L. Meinel, Eur. J. Pharm. Biopharm., 2017, 118, 3-12; (d) R. Motterlini and R. Foresti, Am. J. Physiol., 2017, 312, C302-C313.

8 For leading reviews, see: (a) C. C. Romao, W. A. Blattler, J. D. Seixas and G. J. Bernardes, Chem. Soc. Rev., 2012, 41, 3571-3583; (b) U. Schatzschneider, Br. J. Pharmacol., 2015, 172, 1638-1650; (c) K. Ling, F. Men, W.-C. Wang, Y.-Q. Zhou, H.-W. Zhang and D.-W. Ye, J. Med. Chem., 2018, 61(7), 2611-2635; (d) X. Ji and B. Wang, Acc. Chem. Res., 2018, 51, 1377-1385; (e) C. P. Hopper, L. K. De La Cruz, K. V. Lyles, L. K. Wareham, J. A. Gilbert, Z. Eichenbaum, M. Magierowski, R. K. Poole, J. Wollborn and B. Wang, Chem. Rev., 2020, 120, 13273-13311, and ref. cited therein; for selected recent work, see also:; $(f)$ X. Ji, C. Zhou, K. Ji, R. E. Aghoghovbia, Z. Pan, V. Chittavong, B. Ke and B. Wang, Angew. Chem., Int. Ed., 2016, 55, 15846-15851; (g) X. Ji, K. Damera, Y. Zheng, B. Yu, L. E. Otterbein and B. Wang, J. Pharm. Sci., 2016, 105, 406-416; (h) L. K. C. De La Cruz, S. L. Benoit, Z. Pan, B. Yu, R. J. Maier, X. Ji and B. Wang, Org. Lett., 2018, 20, 897-900; (i) L. K. De La Cruz, X. Yang, A. Menshikh, M. Brewer, W. Lu, M. Wang, S. Wang, X. Ji, A. Cachuela, H. Yang, D. Gallo, C. Tan, L. Otterbein, M. de Caestecker and B. Wang, Chem. Sci., 2021, 12, 10649-10654.

9 (a) X. Ji, Z. Pan, C. Li, T. Kang, L. K. C. De La Cruz, L. Yang, Z. Yuan, B. Ke and B. Wang, J. Med. Chem., 2019, 62, 3163-3168; (b) X. Wang, X. Chen, L. Song, R. Zhou and S. Luan, J. Mater. Chem. B, 2020, 8, 9325-9334; (c) S. Romanski, B. Kraus, U. Schatzschneider, J. M. Neudörfl, S. Amslinger and H.-G. Schmalz, Angew. Chem., Int. Ed., 2011, 50, 2392-2396; (d) N. S. Sitnikov, Y. Li, D. Zhang, B. Yard and H.-G. Schmalz, Angew. Chem., Int. Ed., 2015, 54, 
12314-12318; (e) N. S. Sitnikov, Y. B. Malysheva, A. Y. Fedorov and H.-G. Schmalz, Eur. J. Org. Chem., 2019, 6830-6837.

10 (a) S. Romanski, H. Rücker, E. Stamellou, M. Guttentag, J.-M. Neudörfl, R. Alberto, S. Amslinger, B. Yard and H.-G. Schmalz, Organometallics, 2012, 31, 5800-5809; (b) S. Romanski, B. Kraus, M. Guttentag, W. Schlundt, H. Rucker, A. Adler, J.-M. Neudörfl, R. Alberto, S. Amslinger and H.-G. Schmalz, Dalton Trans., 2012, 41, 13862-13875.

11 S. Romanski, E. Stamellou, J. T. Jaraba, D. Storz, B. K. Krämer, M. Hafner, S. Amslinger, H.-G. Schmalz and B. A. Yard, Free Radical Biol. Med., 2013, 65, 78-88.

12 B. Bauer, A.-L. Göderz, H. Braumüller, J. M. Neudörfl, M. Röcken, T. Wieder and H.-G. Schmalz, ChemMedChem, 2017, 12, 1927-1930.

13 (a) J. L. Wilson, S. F. Kobeissi, S. Oudir, B. Haas, B. Michel, J.-L. Dubois Randé, A. Ollivier, T. Martens, M. Rivard, R. Motterlini and R. Foresti, Chem. - Eur. J., 2014, 20, 14698-14704; (b) R. Motterlini, A. Nikam, S. Manin, A. Ollivier, J. L. Wilson, S. Djouadi, L. Muchova, T. Martens, M. Rivard and R. Foresti, Redox Biol., 2019, 20, 334-348; (c) Z. El
Ali, A. Ollivier, S. Manin, M. Rivard, R. Motterlini and R. Foresti, Redox Biol., 2020, 34, 101521.

14 F. Munyemana, I. George, A. Devos, A. Colens, E. Badarau, A.-M. Frisque-Hesbain, A. Loudet, E. Differding, J.-M. Damien, J. Rémion, J. Van Uytbergen and L. Ghosez, Tetrahedron, 2016, 72, 420-430.

15 K. Achiwa, P. A. Chaloner and D. Parker, Organomet. Chem., 1981, 218, 249-260.

16 A. Madaan, R. Verma, A. T. Singh, S. K. Jain and M. Jaggi, J. Biol. Methods, 2014, 1, e1.

17 T. Wieder, C. E. Orfanos and C. C. Geilen, J. Biol. Chem., 1998, 273, 11025-11031.

18 A. Loboda, A. Jozkowicz and J. Dulak, Vasc. Pharmacol., 2015, 74, 11-22.

19 K. Ghoreschi, J. Brück, C. Kellerer, C. Deng, H. Peng, O. Rothfuss, R. Z. Hussain, A. R. Gocke, A. Respa, I. Glocova, N. Valtcheva, E. Alexander, S. Feil, R. Feil, K. Schulze-Osthoff, R. A. Rupec, A. E. Lovett-Racke, R. Dringen, M. K. Racke and M. Röcken, J. Exp. Med., 2011, 208, 2291-2303.

20 A. Madaan, R. Verma, A. T. Singh, S. K. Jain and M. Jaggi, J. Biol. Methods, 2014, 1, e1. 